\title{
A FAMÍLIA E SUAS CONTRIBUIÇÕES PARA APRENDIZAGEM ESCOLAR NA EDUCAÇÃO INFANTIL: UM ESTUDO DE CASO NA REDE PÚBLICA MUNICIPAL DE FORTALEZA - CEARÁ
}

\author{
THE FAMILY AND ITS CONTRIBUTIONS TO SCHOOL LEARNING IN CHILDHOOD \\ EDUCATION: A CASE STUDY IN THE MUNICIPAL PUBLIC GRID OF FORTALEZA - \\ CEARÁ
}

\author{
Mirandy Vieira Coelho de Meneses ${ }^{1}$ \\ Marcel Pereira Pordeus ${ }^{2}$ \\ Juliana Márcia Alencar Talmag ${ }^{3}$
}

\begin{abstract}
RESUMO: Esta pesquisa é um recorte de minha dissertação de mestrado na Universidad Interamericana, para tanto, contamos com o apoio de dois pesquisadores na área da educação, para a produção e fragmentação dos assuntos mais relevantes para construção deste artigo. A família é o primeiro espaço de socialização que acontece na infância, a partir das interações, padrões de comportamento, valores e costumes que serão transmitidos para o desenvolvimento da personalidade do indivíduo. Portanto, a relevância deste trabalho encontra-se no esclarecimento de questões educacionais a partir do tema "A família e suas contribuições para aprendizagem escolar na Educação Infantil: um estudo de caso na rede pública municipal de Fortaleza - Ceará". Objetivou-se averiguar as contribuições da família no processo de aprendizagem escolar na Educação Infantil (doravante EI). A pesquisa foi realizada numa creche pública do município de Fortaleza, Ceará no período de janeiro a dezembro de 2017. Nos embasamos em revisão da literatura que trata da temática, a partir da metodologia utilizada por meio da Pesquisa Bibliográfica e do referencial teórico e metodológico embasado em autores, tais como: Ariès (1973), Bock (200I), Kaloustian (2000), e com os estudos dos teóricos como Jean Piaget. Posteriormente, a segunda etapa do estudo ocorreu através de observação de um grupo de crianças em seu cotidiano escolar com o intuito de relacionar seu desempenho com as assertivas dos autores e pesquisadores deste trabalho. Ao averiguar as informações adquiridas na pesquisa foi possível constatar que as crianças bem assistidas pelas famílias, e que estas demonstravam preocupação com seu desenvolvimento, valorizando e reconhecendo a importância da EI, foram as que tiveram melhores resultados no seu processo de
\end{abstract}

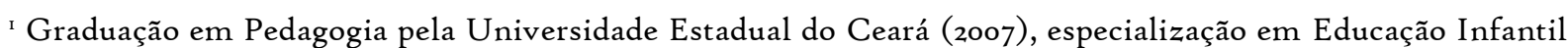
pelo Centro Universitário 7 de setembro (2013) e mestrado em Ciências da Educação pela Universidad Interamericana(2018).E-mail:mirandymeneses@gmail.com.

${ }^{2}$ Mestrando em Planejamento e Políticas Públicas pela Universidade Estadual do Ceará (UECE). Graduado em Letras: Português / Literaturas pela Universidade Federal do Ceará (UFC). E-mail: marcelppordeus@hotmail.com.

3 Possui graduação em Pedagogia pela Universidade Estadual Vale do Acaraú (20oI) e Mestrado em Ciências da Educação pela Universidad Interamericana. E-mail: rucheliana@terra.com.br.
} 
aprendizagem escolar. Já as crianças com menor incentivo dos familiares apresentaram progressos discretos e graduais, percebidos nas avaliações das professoras. Conclui-se que a família pode influenciar, positivamente ou negativa no processo de aprendizagem escolar das crianças dependendo da sua postura para com elas e com a instituição escolar.

Palavras-chave: Família. Aprendizagem escolar. Educação Infantil.

ABSTRACT: This research is an excerpt from my master's dissertation at the Universidad Interamericana, so we have the support of two researchers in the field of education, for the production and fragmentation of the most relevant subjects for the construction of this article. The family is the first socialization space that takes place in childhood, based on the interactions, behavior patterns, values and customs that will be transmitted for the development of the individual's personality. Therefore, the relevance of this work is to clarify educational issues based on the theme "The family and its contributions to school learning in Early Childhood Education: a case study in the municipal public network of Fortaleza - Ceará". The objective was to investigate the family's contributions to the school learning process in Early Childhood Education (hereinafter EI). The research was carried out in a public daycare center in the city of Fortaleza, Ceará, from January to December 2017. We are based on a literature review that deals with the theme, based on the methodology used through the Bibliographic Research and the theoretical and methodological framework in authors such as: Ariès (1973), Bock (200I), Kaloustian (2000), and with the studies of theorists like Jean Piaget. Subsequently, the second stage of the study occurred through the observation of a group of children in their school routine in order to relate their performance to the statements of the authors and researchers of this work. When investigating the information acquired in the research, it was possible to verify that children well assisted by families, and that they showed concern for their development, valuing and recognizing the importance of EI, were the ones that had the best results in their school learning process. Children with less incentive from family members showed discreet and gradual progress, perceived in the teachers' assessments. It was concluded that the family can influence, positively or negatively, the children's school learning process depending on their attitude towards them and the school institution.

Keywords: Family. School learning. Child education.

\section{INTRODUÇÃO}

A relação entre família e escola é um assunto frequentemente abordado na discussão atual acerca do sucesso das crianças no processo de aprendizagem escolar. Neste contexto, investe-se bastante no estudo acerca da participação da família perante a EI, a fim de possibilitar uma educação de qualidade. Desta forma, a família precisa, com a instituição escolar, assumir sua responsabilidade na formação de seus filhos. A maioria dos pais, consciente ou inconscientemente, está cada vez mais deixando a educação como responsabilidade da instituição escolar e dos educadores que a compõem, prejudicando substancialmente o processo de aprendizagem das crianças. Já os pais que se 
comprometem e participam ativamente da vida escolar dos filhos, proporcionam um bom desenvolvimento para os mesmos.

Nesse processo as crianças que não são assistidas por suas famílias, geralmente têm mais entraves em relação à concentração, socialização, interação com os outros, desenvolvimento motor e cognitivo, e, consequentemente, apresentam mais dificuldades de aprendizagem. Já as crianças que têm o apoio psicológico, moral, afetivo e cognitivo dos familiares, são mais estimuladas e possuem maior segurança em desenvolver o que é explorado no âmbito escolar. Os profissionais de instituições escolares comumente associam o baixo rendimento das crianças à má estruturação de suas famílias ou à falta de interesse destas pela escolaridade dos filhos. Outra hipótese seria o desconhecimento dos pais em relação à importância da EI para as crianças no que se refere ao seu desenvolvimento. A ausência dos pais às reuniões pedagógicas é um dos fatos que vem acontecendo com frequência no contexto educacional contemporâneo, o que pode ser um indicativo do insuficiente acompanhamento da educação formal das crianças pelas famílias. Delimitando a problemática à EI, primeira etapa da Educação Básica (EB), esta se configura como o âmbito que marca o início da vida escolar das crianças. As instituições desse nível de ensino constituem-se em contextos de desenvolvimento da criança compartilhando com a família a educação da mesma.

De tal modo como as famílias, as instituições de EI, além de prestar ações de cuidado físico, devem criar condições para o seu desenvolvimento integral que inclui aspectos cognitivos, sociais, afetivos e motores. Ao partir do princípio de que a educação é uma prática social, as relações estabelecidas entre família e escola precisam ser consistentes e bem alinhadas em seus objetivos. Partindo do pressuposto de que tanto a família quanto a instituição escolar não são apenas ambientes de transmissão de cultura, de socialização e de conteúdos historicamente construídos, mas também um espaço de construção de identidade, o tema estudado tem por objetivo principal averiguar as contribuições da família no processo de aprendizagem escolar na EI.

Portanto, o presente estudo consiste numa pesquisa a respeito da influência que a família exerce sobre o processo de aprendizagem escolar na EI, apontando aspectos fundamentais da relação entre este grupo social primário e um Centro de Educação Infantil (CEI), buscando apresentar como ocorre essa parceria e suas implicações na educação formal e no desenvolvimento pleno das crianças. Para a obtenção de respostas aos objetivos apontados neste trabalho, foi desenvolvida uma pesquisa de caráter bibliográfico com a realização de levantamentos e estudos de materiais com dados já analisados e publicados por meios escritos e midiáticos sobre o tema delimitado. Também foi 
elaborada uma pesquisa de campo na qual o ambiente para a coleta de dados foi um CEI da rede pública de ensino do município de Fortaleza, Ceará, e teve como sujeitos da pesquisa um grupo de professoras, famílias e crianças atendidas em turmas do Infantil IV.

$\mathrm{O}$ interesse por esse tema surgiu desde o início da experiência da pesquisadora enquanto professora, lecionando na EI há mais de ro (dez) anos, inicialmente na rede privada de ensino e atualmente na rede pública do município de Fortaleza - Ceará, sendo possível verificar diversas questões relacionadas à família e ao processo de aprendizagem na EI. Algumas questões como o baixo desempenho das crianças, a falta de apoio da realização das atividades de casa, o não atendimento as solicitações da instituição escolar, e como a família pode influenciar do processo de aprendizagem, bem como quais as contribuições da EI e da relação entre família e instituição escolar, motivaram o desenvolvimento desta pesquisa. Por se tratar de grupos sociais fundamentais na formação do seu humano, tanto as famílias quanto as instituições educacionais, refletem o que a sociedade impõe, conforme seus paradigmas e princípios vigentes que fundamentam as necessidades dos indivíduos.

\section{ESCOLA, FAMÍLIA E SOCIEDADE: UM TRIPÉ FUNDAMENTAL}

Constantemente a instituição familiar passa por transformações que ocorrem devido às mudanças socioculturais e tecnológicas, cujas variáveis ambientais, sociais, econômicas, culturais, políticas e/ou religiosas determinam as distintas estruturas e composições da família. Em meio a essas mudanças no âmbito social, a instituição escolar configura-se como um instrumento essencial para equilibrar desarranjos, posto que cumprir suas funções no campo educacional é passível de proporcionar o desenvolvimento das potencialidades humanas formando sujeitos críticos, reflexivos e atuantes nas transformações da sua realidade. Cidadãos conscientes do meio em que vivem e convivem contribuem significativamente com o fortalecimento do tripé escola-família-sociedade, que é a base mais sólida e eficaz para o progresso da sociedade contemporânea. Diante deste cenário, a família, enquanto grupo social primário, é uma das estruturas que forma o ser humano, por conseguinte, deve-se voltar uma grande atenção à influência que esta instituição exerce na esfera educacional. A relevância deste trabalho encontra-se no esclarecimento de questões educacionais, fazendo com que a sociedade tenha a capacidade de identificar e solucionar problemas que aparentemente são superficiais, mas que podem abalar profundamente o desenvolvimento dos 
indivíduos em diversos aspectos e reconhecer o que pode ser feito para melhorar a educação a longo prazo.

A família é considerada como o primeiro sistema no qual um padrão de atividades, papéis e relações interpessoais são vivenciados pela pessoa em desenvolvimento, e cujas trocas dão base para o estudo do desenvolvimento do indivíduo. Para o teórico, “[...] essa visão permite perceber que a criança desenvolve relacionamentos não apenas com a mãe, mas também com outros agentes sociais, como pai, avós e irmãos, sendo tais relacionamentos também relevantes para seu desenvolvimento infantil" (SIGOLO, 2004, p. I89).

\section{I Contexto histórico e social da família}

O termo 'família' é derivado do latim famulus, que significa 'escravo doméstico'. Este termo foi criado na Roma Antiga para assinalar um novo grupo social que surgiu entre as tribos latinas, ao adentrarem na agricultura e na escravidão legalizada. Segundo Alves (1977, p. 282): "No direito romano clássico, a 'família natural' cresce de importância - esta família é baseada no casamento e no vínculo de sangue". A família natural é o agrupamento constituído apenas dos cônjuges e de seus filhos. A família natural tem, por base, o casamento e as relações jurídicas dele resultante, entre os cônjuges, e pais, e filhos.

A família é um grupo social constituído por indivíduos com ascendentes em comum e/ou unidos por vínculos afetivos e que, normalmente, vivem e convivem na mesma residência. Constituindo uma das unidades básicas da sociedade, a família é uma das mais antigas e mais importantes instituições humanas, e desde os tempos pré-históricos é a organização básica da sociedade. Na maioria das vezes as pessoas crescem em uma família e, quando adultas, estabelecem suas próprias famílias. A vida familiar teve início, entre os homens pré-históricos, há mais de 300 mil anos. Esta instituição pode ter sido desenvolvida por conta dos cuidados necessários à criança e dos fortes vínculos entre mãe e filho. Todos os membros tinham que trabalhar para garantir a sobrevivência desse grande grupo (ALVES, 1977).

A família é uma instituição social e historicamente passível de mudanças, estas ocorrem de acordo com as diferentes relações estabelecidas entre os homens. Ariès (1973) realizou um estudo acerca da história social da família, apresentando as grandes transformações que ocorreram na medida em que esta instituição modificou suas relações com a criança, desde o período medieval até o século XX. De acordo com estes estudos, aconteceram mudanças consideráveis em relação à atitude 
da família para com a criança. A partir do século XV foi constatado que as famílias costumavam enviar suas crianças para casas alheias e recebiam crianças de outra família em seu próprio lar.

Desta forma deveriam aprender boas maneiras e prestar serviço para outras famílias, tendo como obrigação servir bem e devidamente ao mestre, chefe da casa na qual residia. Ela aprendia o que o mestre fosse lhe ensinar, podendo ser um aprendiz, um pensionista ou um criado. Havia apenas algumas variações na noção do serviço, que poderia referir-se também ao serviço doméstico, o que não implicava nenhuma degradação ou repugnância. O serviço doméstico e a aprendizagem eram confundidos como formas comuns de educação. Desta forma, Ariès (1973, p. 228) afirma:

Era através do serviço doméstico que o mestre transmitia a uma criança, não ao seu filho, mas ao filho de outro homem, a bagagem de conhecimentos, a experiência prática e o valor humano que pudesse possuir. Assim, toda a educação se fazia através da aprendizagem, e dava-se a essa noção um sentido muito mais amplo do que o que ela adquiriu mais tarde.

É importante salientar que a partir dos séculos XV e XVI, os serviços subalternos começaram a se diferenciar dos ofícios mais nobres. Até o século XVIII o serviço ocupou um lugar considerável nos manuais de civilidade e dos tratados de boas maneiras. Todos os serviços domésticos eram realizados indiferentemente pelas crianças e por empregados remunerados. Em relação à educação medieval, a escola era uma exceção, pois a aprendizagem geralmente ocorria nas casas dos mestres. Dos clérigos que eram enviados à escola, muitos eram confiados, assim como os outros aprendizes, a um padre a quem deveriam servir. O serviço fazia parte da educação de um clérigo tanto quanto a escola.

Segundo Ariès (1973), a transmissão do conhecimento ocorria geralmente de uma geração à outra e era garantida pela participação familiar das crianças na vida dos adultos. Desta forma, as crianças misturavam-se aos adultos para aprender, o que ocorria também nas classes dos colégios. Havia classes nas quais crianças e adultos aprendiam juntos. Nesta época, a criança por volta dos sete até catorze ou dezoito anos, era educada por outras pessoas e dificilmente retornava à sua própria família. Assim, a família não tinha como alimentar um sentimento mais profundo entre pais e filhos, o que não significava que os pais não os amassem ou que não fossem atendidas as suas necessidades. Entretanto, a relação familiar era mais que sentimental; apresentava uma realidade moral e social e se distinguia conforme seu status, ou seja, havia uma diferença considerável entre as famílias pobres em relação aquelas com alto poder aquisitivo. Ariès (1973, p. 23i) explica que:

No caso de famílias muito pobres, ela não correspondia a nada além da instalação material do casal no seio de um meio mais amplo, a aldeia, a fazenda, o pátio ou a 
"casa" dos amos e dos senhores, onde esses pobres passavam mais tempo do que em sua própria casa [...]. Nos meios mais ricos a família se confundia com a prosperidade do matrimônio, a honra do nome.

Conforme supracitada afirmação, os grupos familiares transpareciam uma forma padronizada de se apresentar no seu grupo social, aquilo que parecesse mais aceitável, que concordasse com os princípios e valores impostos pela sociedade. $\mathrm{O}$ século $\mathrm{XV}$, entretanto, principiaria as transformações relativas às realidades e emoções da família. O fator essencial para essa mudança refere-se à extensão da assiduidade escolar. As instituições educacionais ficaram em evidência. A educação foi ficando paulatinamente a cargo da instituição educacional. Esta deixou de ser restrita aos clérigos para se tornar uma ferramenta importante na iniciação social, fazendo a passagem do estado da infância para a fase adulta (ARIÈS, 1973).

Essa evolução deve-se à preocupação com o pudor e o cuidado em não ferir a inocência infantil. Neste período procurou-se separar as crianças dos adultos para treiná-las a resistir melhor às tentações dos adultos. Ela correspondeu também a uma preocupação dos pais em ficar mais perto dos seus filhos e de não os abandonar mais aos cuidados de outra família. Ainda segundo Ariès (1973, p. 232) apresenta essa aproximação dos pais e dos filhos com a presença mais evidente da escola. A substituição da aprendizagem pela escola exprime também uma aproximação da família e das crianças, do sentimento da família e do sentimento da infância, outrora separados. A família concentrou-se em torno da criança.

A iniciação das crianças na cultura, nos valores e nas normas de sua sociedade começa na família. Entre outros grupos sociais, a família, quando bem organizada, dispõe das melhores condições e dos recursos mais eficazes para educar novas gerações. Para um desenvolvimento completo e harmonioso de sua personalidade, a criança deve crescer num ambiente familiar, numa atmosfera de felicidade, amor e compreensão.

Por assumir papel fundamental na sociedade - é a chamada célula máter da sociedade - a família é forte transmissora de valores ideológicos. A função social atribuída à família é transmitir os valores que constituem a cultura, as ideias dominantes em determinado momento histórico [...] (BOCK, 200I, p. 249).

Segundo Bock (200I), uma das grandes responsabilidades da família é a formação física e psíquica do ser humano, sendo assim o elo entre o indivíduo e a sociedade da qual faz parte. Como função mediadora entre o indivíduo e a sociedade, a família deve promover a superação do egocentrismo infantil, proporcionando a formação de um adulto apto para o convívio social. Desta 
forma, essa estrutura basilar constitui o primeiro e o mais importante grupo social do indivíduo, sendo um quadro de referência estabelecido por meio das relações e identificações que a criança criou durante o desenvolvimento. A família vem se transformando através dos tempos, acompanhando as mudanças religiosas, econômicas e sociais do contexto em que se encontra inserida. É um espaço sociocultural que deve ser continuamente renovado e reconstruído conforme as necessidades vigentes da sociedade da qual é proveniente.

\section{A FAMÍlIA E SUAS RELAÇÕES COM A EDUCAÇÃO}

A família é o primeiro e o mais importante grupo social, essencial na construção dos princípios e dos valores que permanecerão na vida de cada ser humano. É o espaço indispensável para o desenvolvimento e a proteção integral dos filhos e demais membros, independente do arranjo ou da estrutura familiar. Segundo Kaloustian (2000, p. I2), “[...] é a família que propicia os aportes afetivos e, sobretudo materiais necessários ao desenvolvimento e bem-estar dos seus componentes." Ela desempenha um papel crucial na educação formal e informal. É nesse grupo que são transmitidos valores éticos e humanitários, e nele se estreitam e fortalecem vínculos de solidariedade.

Entre os grupos sociais, a família, quando bem organizada, dispõe das melhores condições e dos recursos mais eficazes para educar as novas gerações. Quando unido pelos laços de amor, confiança e compreensão, o grupo familiar é o espaço ideal para a educação da criança. Uma boa aprendizagem independe do nível social e econômico no qual se encontra a família. Existem fatores mais relevantes que dão condições favoráveis para o desenvolvimento desse processo. $O$ primeiro contato com o direito aos cuidados necessários para o crescimento e desenvolvimento físico, psíquico e social da criança e do adolescente se procedem na família, assim como os primeiros hábitos e costumes da cultura também são concebidos dentro desta instituição.

Segundo Mutschele (1988, p. 335), “[...] a função educativa da família não representa, por conseguinte, apenas um dever e um direito da mesma. É também resultado vivo e espontâneo de sua própria natureza psicológica e social". O processo de aprendizagem enfrentado pelas crianças é algo muito delicado, que exige atenção e dedicação para que não seja prejudicado pela instabilidade na qual a sociedade se encontra. 


\section{CONCLUSÃO}

A família se constitui como o núcleo primário da construção do ser humano, exercendo forte influência na transmissão e fixação de valores, bem como na educação formal e informal. Essa influição pode ser positiva ou negativa dependendo do comportamento e atuação desse grupo social na vida escolar das crianças, sendo necessário que os pais tenham o compromisso de estabelecer bases sólidas sobre as quais apoiarão a formação dos seus filhos.

Nessa construção, para que a sua atuação seja a mais benéfica possível, a instituição escolar deve elaborar projetos e criar mecanismos para que participem ativamente da dinâmica educacional das crianças. Partindo do objetivo do trabalho de averiguar as contribuições da família no processo de aprendizagem escolar na EI, serão mencionadas algumas considerações relevantes contemplando a verificação da significância de questões lançadas no início do estudo. Em relação ao que foi pesquisado acerca de aprendizagem e desenvolvimento infantil, foi possível perceber que há várias formas de compreender esses dois processos conforme foi aferido com os estudos de fundamentação teórica.

Em contrapartida, é possível constatar numa visão geral, que estes processos são baseados nos aspectos, físico, cognitivo, afetivo e social do ser humano, e que eles se relacionam intimamente durante a evolução humana. O desenvolvimento desses aspectos é possibilitado pela família que, além de dar à criança condições mínimas para a sua sobrevivência, é a base na qual o indivíduo toma como referência para a vida toda. Estudando a família numa abordagem histórica e cultural, foi possível compreender como este grupo foi, ao longo dos tempos, se formando, se transformando e, cada vez mais, exercendo influência sobre a sociedade, visto que esta instituição primária tem como função social transmitir valores culturais e ideias dominantes de um determinado momento histórico.

Com os estudos realizados no presente trabalho, evidenciou-se que a família é o primeiro espaço no qual a criança desenvolve padrões de socialização. Desta forma, ela interage com o meio e se envolve com todo conhecimento adquirido durante suas iniciais experiências de vida que vão refletir na sua caminhada escolar. Por conseguinte, os possíveis progressos advindos das funções da instituição educativa dependem da ativa e concreta colaboração familiar. Através da pesquisa bibliográfica constataram-se referentes à família no processo de aprendizagem escolar. Percebeu-se, portanto, que a aprendizagem é um processo complexo que envolve muitas variáveis que se 
interligam e que ocorre dentro de cada indivíduo. Está sujeito à influência de fatores internos e externos, individuais e sociais. Por conseguinte, a escola deve proporcionar um ambiente propício à participação da família, incentivando-a a estar sempre envolvida e conscientizando-a da sua importância no processo de aprendizagem das crianças. Assim como esse grupo social também deve buscar os melhores caminhos para poder colaborar efetivamente com o desempenho escolar dos filhos. Ressalta-se que, as instituições familiar e escolar, mesmo com objetivos em comum, cada uma exerce funções específicas; devem fazer sua parte de modo a possibilitar uma caminhada passivelmente exitosa, e assim conduzir as crianças a um futuro promissor.

Em consonância, as análises de dados coletados da pesquisa numa abordagem qualitativa, comprovaram os estudos de embasamento teórico. Nesse momento do trabalho, ao investigar a relevância da família no âmbito educacional, e mais especificamente na EI, foi averiguado ser inquestionável a importância do grupo familiar para a educação das crianças. A pesquisa de campo permitiu o conhecimento da realidade escolar, a dinâmica em sala de aula e as famílias de algumas crianças viabilizando analisar dados e estabelecer resultados reais e consistentes sobre o assunto em pauta.

É importante destacar que o CEI no qual foi realizada a pesquisa tem a preocupação de estar em permanente contato com as famílias que atende, pois, acredita que essa comunicação constante é fundamental para a educação das crianças. Isso favorece significativamente a participação efetiva dos familiares no processo de aprendizagem escolar. Destaca-se que a instituição escolar deve ter a preocupação e a iniciativa de estar sempre em contato com as famílias, motivando e propiciando momentos de aproximação, pois essa comunicação constante é essencial para a consolidação da educação e para o desenvolvimento pleno das crianças. Ainda neste eixo reflexivo, quanto à educação, família e escola completam-se. Estes dois grupos devem estabelecer uma relação estreita de colaboração e harmonia para que as crianças tenham uma boa formação. Ambos devem apresentar interesse, compreender e contribuir com o processo de aprendizagem das crianças para que estas se mostrem seguras e disponíveis a aprender, contando com o apoio e a colaboração constantes dos seus responsáveis em todas as suas atividades.

O presente estudo teve como limitação a pesquisa com população reduzida e em um único campo. Contudo, por meio deste foi possível instigar diversos grupos sociais, bem como famílias, instituições escolares, ampliando-se à comunidade e a todos os envolvidos com a EI a conhecerem e valorizarem este nível primário de ensino da $\mathrm{EB}$, bem como o papel imprescindível da família para 
o alcance de uma educação de qualidade. Permitiu-se refletir de forma mais aprofundada sobre o desenvolvimento da criança atrelando-o à organização familiar.

Nesse viés, concluímos que a família precisa estar bem estruturada, ou seja, ter um bom relacionamento entre os seus membros, e convívio harmônico e saudável para ser capaz de oferecer todos os suportes necessários para a formação da criança. Nesse contexto, professores e demais profissionais do campo educacional precisam atuar de forma a possibilitar a sintonia de ações através de estratégias que aproximem os pais da educação de seus filhos. Estes, em especial, gestores das instituições de EI, precisam promover reuniões constantes, palestras, entre outros momentos de diálogo e interação entre famílias, crianças e docentes. Outra estratégia que se destacou no resultado da pesquisa e que pode ser ampliada para todo o CEI é a divulgação de atividades por registros fotográficos e filmagens postados através da internet para que os pais tenham acesso e conheçam o cotidiano escolar dos filhos concretamente.

O ideal é que pais e educadores tracem metas de forma simultânea para propiciar a segurança e os aportes necessários na aprendizagem escolar e, consequentemente, formar cidadãos críticos e atuantes na construção de uma sociedade mais justa e consciente. Desta forma, estes dois pilares na constituição do indivíduo serão parceiros na efetivação do processo de aprendizagem escolar. Conclui-se que a família é um grupo inquestionavelmente influente na formação humana, que contribui não apenas com a aprendizagem escolar, mas também é fundamental para o alcance da finalidade da EI, o desenvolvimento integral das crianças em seus aspectos, físico, psicológico, intelectual e social.

\section{REFERÊNCIAS}

ALVES, José Carlos Moreira. Direito Romano. Rio: Forense, 1977.

ARIÈS, Philippe. História social da criança e da família. Tradução: Dora Flaksman. Ed. Guanabara Koogan, 1973.

BOCK, A. M.; FURTADO, O.; TEIXEIRA, M. de L. Psicologias - Uma introdução ao estudo de psicologia. São Paulo: Saraiva, 13. ed., 2001.

CEARÁ. Secretaria da Educação. Orientações Curriculares para a Educação Infantil. Fortaleza: SEDUC, 201 .

KALOUSTIAN, Sílvio Manoug (org). Família Brasileira, a base de tudo. 4. ed. São Paulo: Cortez; Brasília, DF: UNICEF, 2000. 
MUTSCHELE, Marly Santos. Problemas de aprendizagem da criança. São Paulo: Loyola, 1988.

SIGOLO, S. R. R. L. Favorecendo o desenvolvimento infantil: ênfase nas trocas interativas no contexto familiar. In: E. G. Mendes, M. A. Almeida \& L. C. A. Williams (Org.). Temas em Educação Especial: avanços recentes, p.ı89-195. São Carlos: Edufscar. 2004 . 